\title{
Early-life chemical exposures and risk of metabolic syndrome
}

\author{
Nicole E De Long \\ Alison C Holloway \\ Department of Obstetrics and \\ Gynecology, McMaster University, \\ Hamilton, ON, Canada
}

This article was published in the following Dove Press journal: Diabetes, Metabolic Syndrome and Obesity:Targets and Therapy 2I March 2017

Number of times this article has been viewed

Correspondence: Alison C Holloway Department of Obstetrics and Gynecology, McMaster University, RM HSC-3N52, 1280 Main Street West, Hamilton, ON L8S 4KI, Canada $\mathrm{Tel}+\mathrm{I} 9055259140$ ext 22130 Fax + I 905524291 I Email hollow@mcmaster.ca

\begin{abstract}
The global prevalence of obesity has been increasing at a staggering pace, with few indications of any decline, and is now one of the major public health challenges worldwide. While obesity and metabolic syndrome (MetS) have historically thought to be largely driven by increased caloric intake and lack of exercise, this is insufficient to account for the observed changes in disease trends. There is now increasing evidence to suggest that exposure to synthetic chemicals in our environment may also play a key role in the etiology and pathophysiology of metabolic diseases. Importantly, exposures occurring in early life (in utero and early childhood) may have a more profound effect on life-long risk of obesity and MetS. This narrative review explores the evidence linking early-life exposure to a suite of chemicals that are common contaminants associated with food production (pesticides; imidacloprid, chlorpyrifos, and glyphosate) and processing (acrylamide), in addition to chemicals ubiquitously found in our household goods (brominated flame retardants) and drinking water (heavy metals) and changes in key pathways important for the development of MetS and obesity.
\end{abstract}

Keywords: obesity, pesticides, polybrominated diphenyl ethers, heavy metals, acrylamide, endocrine-disrupting chemicals

\section{Introduction}

The global prevalence of obesity has been increasing at a staggering pace, with few indications of any decline, and is now one of the major public health challenges worldwide. Most alarmingly, the list of adverse consequences related to overweight and obesity continues to grow. ${ }^{1-3}$ It is well accepted that obesity is a risk factor for other metabolic abnormalities, including an increased risk of metabolic syndrome (MetS). ${ }^{4}$ MetS is a cluster of interrelated metabolic risk factors. MetS as defined by a joint interim statement of the International Diabetes Federation Task Force on Epidemiology and Prevention, the National Heart, Lung, and Blood Institute, the American Heart Association, the World Heart Federation, the International Atherosclerosis Society, and the International Association for the Study of Obesity includes three of the following five clinical findings: elevated waist circumference, elevated triglycerides, reduced HDL cholesterol, elevated blood pressure, and elevated fasting glucose. ${ }^{4}$ Many of these components of MetS are interrelated, for example, obesity is strongly related to insulin resistance, which is a wellestablished risk factor for type 2 diabetes. ${ }^{5}$ The worldwide prevalence estimates vary, but the International Diabetes Federation estimates that one-quarter of adults worldwide have MetS. ${ }^{6}$ Most alarmingly, people with MetS have a significantly increased risk of developing chronic metabolic diseases, including non-alcoholic fatty liver disease (NAFLD), type 2 diabetes, and cardiovascular disease. ${ }^{7}$ In addition, obesity has been associated 
with cancer, rheumatoid arthritis, infertility, and depression, among others. ${ }^{8-10}$ The path to MetS is complex, but there is now compelling evidence from human epidemiological studies and animal experiments to support the hypothesis that exposure of the fetus to certain hormonal, nutritional, metabolic, and environmental conditions may permanently alter the physiology of the resulting offspring and lead to an increased risk of chronic metabolic disease in later life. Clearly, understanding the environmental factors that contribute to the rise in obesity and MetS is critically important.

\section{Endocrine-disrupting chemicals (EDCs) as metabolic disruptors}

Although the obesity epidemic has historically thought to be largely driven by increased caloric intake and lack of exercise, this is insufficient to account for the observed changes in disease trends. There is now considerable evidence to suggest that early-life exposure to synthetic chemicals in our environment plays an important role in the global epidemic of obesity and MetS. The number of new chemicals that are synthesized and marketed increases exponentially each year; from 2005 to 2015, the number of chemicals registered by the Chemical Abstract Service increased from 25 to 100 million substances. ${ }^{11,12}$ Introduction of chemicals into the environment (aquatic and terrestrial) occurs from industry and manufacturing practices, agricultural use, and human activity (eg, the use of medications, personal care products, and cleaning products). There is now compelling evidence in mammals that exposure to environmental pollutants can alter endogenous hormonal axes. These chemicals have been termed endocrine disruptors. Historically, research attention has focused largely on the ability of these xenobiotic compounds to alter estrogenic and/or androgenic pathways by acting as agonists/antagonists at hormone receptors, altering the number of hormone receptors in a cell-specific manner or causing perturbations in circulating concentrations of the endogenous hormones. ${ }^{13-18}$ More recently, however, there has been an increased awareness that these same chemicals can also disrupt metabolic homeostasis. There are now substantial in vivo and in vitro data demonstrating that environmental chemical pollutants can alter energy homeostasis in mammals through a number of pathways, including central effects on appetite regulation, altered energy expenditure and disruption of glucose, and/or lipid homeostasis in metabolically active tissues (ie, pancreas, liver, and adipose tissue). ${ }^{19-24}$ Indeed, a recent report concluded that in the European Union, exposure to endocrine-disrupting compounds contributes substantially to obesity and diabetes and was associated with estimated health care costs in excess of $€ 18$ billion annually. ${ }^{25}$ Both human and animal studies have shown that exposures to chemical insults have profound effects on key pathways important for the development of MetS.

\section{Environmental chemical exposures during pregnancy and the development of MetS}

In recent years, there has been increasing concern that exposures to environmental chemicals in early life (ie, in utero development and/or infancy) may be associated with chronic metabolic disease in adulthood, leading to increased research attention in this area. There are a number of pathways by which these chemicals may increase the risk of MetS later in life, including, but not limited to, effects on fetal and postnatal growth trajectories, altered organ development and function, and disruption of hormonal axes. For example, epidemiological studies have reported an increased risk of reduced birth weight following exposure to a suite of environmental chemicals, including persistent organic pollutants, pesticides, and air pollution. ${ }^{26-28}$ Importantly, there is now substantial evidence to support the hypothesis that fetal growth retardation is associated with an increased incidence of adult-onset diseases, including obesity, type 2 diabetes, hypertension, coronary heart disease, dyslipidemia, and stroke. ${ }^{29,30}$

In addition to effects on birth weight, many of these environmental chemical pollutant exposures can result in altered tissue development and function independent of low birth weight. For example, Bisphenol A has been shown in epidemiological studies to be associated with increased risk of obesity, and it has also been shown to have direct effects on adipose tissue development (adipogenesis) along with pancreas development and function, leading to an obese, insulin-resistant phenotype. ${ }^{31-33}$ Similarly, phthalates have also been associated with an increased risk of obesity due to their direct effects on liver function (hepatic fat accumulation) and their ability to disrupt thyroid function (dysregulation of energy balance and metabolism). ${ }^{34-36}$

It is clear that the mechanisms leading to MetS following early-life exposure to chemicals in our environment are diverse and multidimensional. The goal of this review is to highlight evidence linking early-life exposure to chemicals in our environment with MetS in the progeny into adulthood. There is considerable evidence linking exposure to polyaromatic hydrocarbons, bisphenol A, phthalates, perfluorinated chemicals, polychlorinated biphenyls (PCBs), 
organochlorine pesticides, and organotins to metabolic perturbations; these chemicals have been recently reviewed in detail elsewhere. ${ }^{37-41}$ In this review, we focus on a suite of chemicals that are common contaminants associated with food production (pesticides) and processing (acrylamides), in addition to chemicals ubiquitously found in our household goods (flame retardants) and drinking water (heavy metals). To complete this narrative review, we used PubMed for our overall basic search for articles published in English using keywords related to the exposures of interest (pesticides, imidacloprid, glyphosate, acrylamide, brominated flame retardants, and heavy metals), the timing of exposure (pregnancy, prenatal, and in utero), and the outcomes of interest (birth weight, fetal outcomes, adipose, insulin, glucose, blood pressure, diabetes, and obesity). We included studies conducted in both animals and humans.

\section{Crop production: pesticides}

The development of new agricultural-related practices has been vital in expanding our food supply and will continue to play a critical role as the world's population grows. Insecticides, herbicides, and fertilizers have enhanced the stability of the food supply chain, but they may also contribute to chronic metabolic diseases. In this section, we highlight emerging evidence to suggest that commonly used pesticides may also contribute to the increased incidence of MetS.

\section{Chlorpyrifos}

Chlorpyrifos is an organophosphate insecticide that inhibits acetylcholinesterase activity. Due to its broad spectrum activity against many foliar and soil insects, it is commonly used worldwide for a pest control in a wide range of field crops and fruit. ${ }^{42}$ Estimated usage in Canada is $100,000-500,000 \mathrm{~kg} /$ year and in the US is 3.2-4.1 million kg/year. ${ }^{42,43}$ Chlorpyrifos has been detected in aquatic ecosystems and in a range of food types, including fruits, vegetables, grains, beans/ nuts/legumes, dairy, and meat/fish/eggs, leading to human exposure as documented by the widespread presence of urinary metabolites of chlorpyrifos in nonoccupationally exposed populations. ${ }^{44-46}$ Chronic occupational exposures to chlorpyrifos have been demonstrated in farmers from Iowa, Vietnam, and Thailand who were found to have significantly higher urinary metabolites of chlorpyrifos and significant transdermal exposure, ${ }^{47,48}$ both of which are likely to have significant adverse health effects. ${ }^{49}$

The postnatal metabolic effects of chlorpyrifos exposure during pregnancy are largely unknown due to the absence of human epidemiological studies. However, rodent studies suggest that this is an important concern. Prenatal exposure to chlorpyrifos in rats caused hyperlipidemia and hyperinsulinemia, leading to MetS into adulthood. ${ }^{50}$ Moreover, acute and chronic exposures to chlorpyrifos have been shown to be associated with increased body weight, altered lipid homeostasis, and increased blood pressure. ${ }^{51-53}$ Increased fatty acid synthesis and storage have been further substantiated in vitro following chlorpyrifos exposure. ${ }^{54}$ As a result, it is biologically plausible that in humans, early-life exposures to chlorpyrifos may in fact increase the risk of metabolic disturbances. Given its widespread usage and detection in the environment and human samples, further study is warranted.

\section{Imidacloprid}

Imidacloprid is a neonicotinoid insecticide. These insecticides act as agonists of insect nicotinic acetylcholine receptors (nAChRs). Neonicotinoids are widely used in agricultural crop production; in 2008, neonicotinoids accounted for $\sim 25 \%$ of the global insecticide market. ${ }^{55}$ As a result, imidacloprid has been found in terrestrial (soil) and aquatic (surface and groundwater) environments ${ }^{56}$ as well as being widely detected in fruits and vegetables. ${ }^{57}$

Despite the fact that in vitro studies have demonstrated the potential for significant absorption of imidacloprid in the human intestine ${ }^{58}$ and imidacloprid residues are prevalent in many fruits and vegetables, ${ }^{57}$ there has been limited population-based biological monitoring for imidacloprid exposure. Recently, a small study in nonoccupationally exposed adults $(\mathrm{N}=52)$ demonstrated that imidacloprid was present in the urine of $96 \%$ of study participants at levels above the limit of detection. ${ }^{59}$ Historically, neonicotinoids were thought to have limited toxicity for humans due to their high specificity toward insect nAChRs. However, it is now clear that these insecticides also have agonist activity at mammalian $n A C h R s^{60}$ raising the possibility of human health risks associated with chronic exposure to neonicotinoids. In fact, high dose of imidacloprid $(50 \mathrm{mg} / \mathrm{kg})$ induced hepatotoxicity as evidenced by elevated plasma aspartate aminotransferase and alanine aminotransferase levels in rats ${ }^{61}$ In addition, $20 \mathrm{mg} /$ $\mathrm{kg}$ imidacloprid resulted in hepatic necrosis and infiltration of inflammatory markers. ${ }^{62}$ Moreover, given that adipose tissue expresses multiple $\mathrm{nAChR}$ genes, it is possible that imidacloprid may affect lipid homeostasis. ${ }^{63}$ Indeed, a recent study has shown that imidacloprid can promote adipocyte differentiation and lipid accumulation in adipocytes (3T3L1 cells) ${ }^{64}$ While the mechanism(s) have not been clearly 
elucidated, it has been suggested that imidacloprid suppresses the expression of antioxidant enzymes implicating oxidative stress as a significant contributor to the observed metabolic perturbations. ${ }^{65}$

\section{Glyphosate}

Glyphosate is one of the most commonly used herbicides worldwide. It inhibits 5-enolpyruvylshikimate-3-phosphate (EPSP) in the shikimate pathway; a pathway plants and microorganisms require for the synthesis of the aromatic amino acids phenylalanine, tyrosine, and tryptophan. ${ }^{66}$ Glyphosate has been identified in surface and groundwater; ${ }^{67,68}$ however, most nonoccupational exposures occur from consuming foods containing glyphosate residues. ${ }^{69}$

While there are detection methods available to measure serum concentrations of glyphosate and its metabolite aminomethylphosphonic acid (AMPA), few studies have investigated the transfer of maternal-to-fetal exposure during pregnancy. ${ }^{70-72}$ A recent systematic review of observational studies investigating prenatal exposure to glyphosate determined that there is insufficient evidence to conclude that glyphosate does or does not affect pregnancy outcomes, including birth weight. ${ }^{73}$

While the effects of glyphosate on metabolic health in humans have largely not been explored, there are animal and cell culture studies that have investigated the effects of glyphosate on key metabolic pathways. Although glyphosate is thought to have low toxicity to mammals, ${ }^{74}$ it has recently been shown to cause liver and kidney toxicities at low doses. ${ }^{75}$ Results suggest that glyphosate exposure caused liver fibrosis and mitochondrial membrane dysfunction. Furthermore, glyphosate has been shown to increase apoptosis and induce oxidative stress in preadipocytes. ${ }^{76,77}$ Oxidative stress ensues due to mitochondria dysfunction ${ }^{78}$ and decreased oxidative capacity, which has been shown to impair glucose uptake into adipocytes, promoting hyperglycemia. ${ }^{79}$ Oxidative stress also disturbs the adipokine production by fat cells, which has been suggested to be an early initiation event in the development of MetS. ${ }^{80}$ Taken together, these studies suggest that further study of the effects of glyphosate on MetS risk requires further attention.

\section{Food processing}

It is widely accepted that in recent decades, there has been a significant increase in the consumption of processed foods. Food processing intentionally introduces food additives (eg, food dyes, emulsifiers, preservatives, and artificial sweeteners) but also introduces unwanted contaminants as a result of the packaging process (eg, bisphenol A). There is another group of chemicals that are introduced by the nature of the food processing itself; one of these is acrylamide.

\section{Acrylamide}

Acrylamide is produced by the reaction between asparagine and sugar molecules and is formed during food processing. Acrylamide is known to cross the placenta ${ }^{81}$ with nonsignificant amounts transferring to the infant through breast milk. ${ }^{82}$ Rodent models have demonstrated that prenatal and perinatal acrylamide exposures result in low birth weight offspring that develop signs of liver toxicity and lipid accumulation in postnatal life. ${ }^{83,84}$ Meanwhile, administration of acrylamide to adult rodents has been shown to increase glycogen content and increase hepatocyte size in addition to causing dysglycemia and elevated serum lipid levels. ${ }^{85}$ To date, only three studies have investigated the relationship between prenatal acrylamide exposure and fetal growth outcomes in human populations but have, for the most part, shown consistent associations between acrylamide exposure and reduced fetal growth. The MoBa study found that an increased consumption of acrylamide was associated with lower birth weight infants. ${ }^{86}$ Similarly, the NewGeneris study found that maternal and cord blood levels of acrylamide and its metabolite glycidamide correlated with a reduced birth weight and head circumference. ${ }^{87}$ Finally, the most recent study found that maternal dietary acrylamide and birth weight showed a significant negative correlation and that dietary intake of acrylamide was significantly higher in small for gestational age (SGA; <10th percentile) newborns. ${ }^{88}$ Taken together, these results suggest that an increased maternal acrylamide consumption during pregnancy may have the potential to impair fetal growth; however, it still remains to be determined whether SGA as a result of acrylamide exposure in humans is associated with metabolic abnormalities in postnatal life.

\section{Household exposures}

There is an increasing awareness that there are a wide variety of chemical exposures, which occur in the home including exposure to cleaning and personal care products, to chemicals used in consumer products to make them stain resistant or to meet legislated flammability standards and to chemicals in household dust and drinking water. Of these chemicals, we will focus on the evidence linking exposure to polybrominated diphenyl ethers (PBDEs) (flame retardants) and heavy metals to metabolic disease risk. 


\section{PBDEs}

PBDEs have been widely used since the 1970s and are frequently found in mixtures of similar chemicals otherwise called congeners. PBDEs are applied to products, such as fabrics, plastics, household appliances, and electronics, to decrease their flammability. As a result, adults and children are chronically exposed to these chemicals through inhalation of contaminated household dust. ${ }^{89-91}$ Exposure also occurs through hand-tomouth behaviors in adults (ie, biting nails and licking fingers) and toddlers. ${ }^{92,93}$ Serum concentrations of PBDEs have been broadly related to electronic use. More specifically, individuals who used personal computers, audio/video devices, small household appliances, or own flat screen TVs have been shown to have the highest concentration of PBDEs. ${ }^{94}$

In the US, PBDE levels in adults range from 30 to $100 \mathrm{ng} / \mathrm{g}$ lipid and these values are typically higher in children. ${ }^{95}$ PBDEs measured in pregnant women have ranged between 2.44 and $258 \mathrm{ng} / \mathrm{g}$ lipid, while the median concentrations remain between 7.7 and $9.97 \mathrm{ng} / \mathrm{g}$ lipid. ${ }^{96,97}$ PBDEs have been shown to cross the placenta ${ }^{98}$ and the blood-brain barrier, ${ }^{99}$ thus having the potential to impact fetal health and development. In fact, comparing the maternal and cord serum, there is evidence to suggest that fetal exposure is greater compared to the maternal exposure. ${ }^{100}$ More astonishing is that measurable levels of PBCDs are present in the developing fetus as early at 6.5 weeks. ${ }^{101}$

Prenatal exposure to high levels of PBDEs has been associated with preterm birth (odds ratio $=5.6,95 \% \mathrm{CI}: 2.2$, 15.2; $P<0.001)^{102}$ while its effects on birth weight have been inconclusive. In regions where the exposure to PBDEs is higher than the US Environmental Protection Agency Reference dose, exposures have reported a positive correlation between PBDE exposure and birth weight and length ${ }^{103}$ while other regions have shown the opposite relationship ${ }^{104-107}$ or no relationship at all. ${ }^{96,108}$ Furthermore, postnatal exposures to maternal PBDEs through breast milk continue to be a significant source of PBDE congeners. Müller et al ${ }^{103}$ have comprehensively described the reported levels of PBDE congeners in breast milk from countries around the world. Although levels appear to be decreasing over time, levels remain at a level that is concerning for the long-term health outcomes of exposed infants. ${ }^{109}$

There is evidence to suggest that prenatal PBDE exposure may in fact cause metabolic perturbations in the offspring. The lipophilic PBDE has been shown to accumulate in adipose tissue and liver and to alter lipolysis and insulin signaling favoring an obese phenotype. ${ }^{10,111}$ In addition, animals exposed prenatally to PBDEs had an impaired fetal growth $^{112}$ and the subsequent development of obesity and insulin resistance in adulthood. ${ }^{113}$ Similarly, the CHAMACOS study, a longitudinal birth cohort study in California, found that maternal PBDE levels were significantly and differentially associated with weight changes in children at the age of 7 years based on sex. ${ }^{114}$ Another study, the Boston Birth Cohort, examined paired maternal cord blood samples and established that PBDE exposure may result in epigenetic modifications at the promoter region of inflammatory markers, thereby increasing the susceptibility to MetS ${ }^{95}$ Therefore, while it remains to be determined whether PBDE exposure during pregnancy has a significant impact on subsequent metabolic perturbations, long-term data suggest that further studies are warranted.

\section{Metals}

Lead, mercury, and cadmium are three metals that have been widely used in a number of applications leading to widespread contamination of food, water, soil, and air and frequent detection in biomonitoring studies. ${ }^{115}$ For the general population, the most common sources of exposure for these heavy metals are via contaminated air and food, although exposure to tobacco smoke is also a significant source of exposure for cadmium and lead. ${ }^{116,117}$ Although lead levels have been continuously decreasing in North America, ${ }^{118}$ a recent study found that $>99 \%$ of women had detectable blood lead levels during pregnancy. ${ }^{119}$ Similarly, the majority of pregnant women had detectable blood levels of cadmium $(>95 \%)$ and mercury $(>85 \%){ }^{119}$ Given the widespread exposure to cadmium, mercury, and lead, there have been a number of studies investigating the relationship between maternal body burden of these metals and adverse pregnancy outcomes (eg, spontaneous abortion, stillbirth, preterm labor, and low birth weight). As a result, there are now a number of epidemiological studies, which have reported that exposure to these heavy metals is associated with low birth weight. ${ }^{120,121}$ However, these results are not entirely consistent as a number of other studies have failed to find a similar association. ${ }^{121}$

There have been a limited number of epidemiological studies looking at early-life exposure to heavy metals and metabolic perturbations in the children. The few studies that do exist do not suggest that exposure to heavy metals is associated with an increased risk of obesity but may be associated with other components of the MetS, most notably changes in blood pressure. There are two studies that have examined early-life exposure to metals and the development of obesity in the children. In a Spanish prospective birth cohort, there was no association between early-life exposure to cadmium, mercury, or lead and weight (body mass index $Z$-score) at the 
age of 7 years. ${ }^{122}$ Similarly, Afeiche et al ${ }^{123}$ did not report a significant association between prenatal lead exposure and body weight at the age of 5 years. Interestingly, data from NHANES found that in adolescents (aged 6-18 years), both lead and cadmium levels were negatively associated with waist circumference, ${ }^{124}$ although the NHANES measurements do not reflect early-life exposures. There is a paucity of information available regarding the effects of prenatal exposure to metals and glucose homeostasis in the offspring. Faulk et $\mathrm{al}^{125}$ have reported that in mice, exposure to lead during pregnancy and lactation resulted in insulin resistance, but this effect was only observed at one dose and only in the male offspring. There have been several studies that have examined prenatal exposure to cadmium, lead, and mercury and blood pressure in children. To date, these studies have not shown any effect of exposure to cadmium or lead on blood pressure, although they have reported adverse effects on kidney function that may impact blood pressure in later life. ${ }^{126-128}$ In contrast, there is some indication that prenatal exposure to mercury at high levels but not those seen in the general population may result in increased blood pressure in childhood. ${ }^{129,130}$ Although there is widespread exposure to cadmium, lead, and mercury, at this time, there is no enough information from epidemiological studies or animal experiments to determine whether or not these exposures pose a risk for metabolic disease in the offspring.

\section{Conclusion}

There is increasing evidence that early-life exposure to environmental chemicals may play a significant role in the global obesity epidemic. ${ }^{37-41}$ It is important to note that currently, efforts are being made to reduce the exposure to some of these chemicals. For example, the US Pharmacopeia Convention (USP) has announced plans to establish new monitoring for elemental impurities in pharmaceuticals and nutraceuticals by 2018 to reduce human exposure to these harmful metals. ${ }^{131}$ In addition, China has issued the "Soil Ten Plan" to monitor key pollutants (heavy metals and organic pollutants) and improve the soil quality and agriculture practices to improve the long-term health and well-being of their country into $2050 .^{132}$ These initiatives are in line with the 2015 Parma Consensus Statement, which highlighted the importance of modifying exposures to mitigate the potential impact of these chemicals on metabolic diseases. ${ }^{133}$ Although we have focused on a select few chemicals with widespread exposure that have not received substantial attention, there are many other chemicals that have been examined in more detail and been shown to cause metabolic perturbations ${ }^{37-41}$ and many more that have not been evaluated for their ability to disrupt metabolic homeostasis. Therefore, there is clearly an urgent need for a comprehensive research strategy to evaluate the role of environmental chemicals in metabolic diseases.

\section{Disclosure}

The authors report no conflicts of interest in this work.

\section{References}

1. Yanovski JA. Pediatric obesity. An introduction. Appetite. 2015;93: 3-12.

2. NCD Risk Factor Collaboration (NCD-RisC). Trends in adult bodymass index in 200 countries from 1975 to 2014: a pooled analysis of 1698 population-based measurement studies with $19 \cdot 2$ million participants. Lancet. 2016;387(10026):1377-1396.

3. Ranjani H, Mehreen TS, Pradeepa R, et al. Epidemiology of childhood overweight \& obesity in India: a systematic review. Indian JMed Res. 2016;143(2):160-174.

4. Alberti KG, Eckel RH, Eckel RH, et al. Harmonizing the metabolic syndrome: a joint interim statement of the International Diabetes Federation Task Force on Epidemiology and Prevention; National Heart, Lung, and Blood Institute; American Heart Association; World Heart Federation; International Atherosclerosis Society; and International Association for the Study of Obesity. Circulation. 2009;120(16):1640-1645.

5. Smith U, Kahn BB. Adipose tissue regulates insulin sensitivity: role of adipogenesis, de novo lipogenesis and novel lipids. J Intern Med. 2016;280(5):465-475.

6. International Diabetes Federation Task Force on Epidemiology and Prevention. Metabolic Syndrome. 2006:1-24. Available from: https:// www.idf.org/webdata/docs/IDF_Meta_def_final.pdf. Accessed January 27, 2017.

7. Kaur J. A comprehensive review on metabolic syndrome. Cardiol Res Pract. 2014;2014:943162.

8. Arnold M, Leitzmann M, Freisling H, et al. Obesity and cancer: an update of the global impact. Cancer Epidemiol. 2016;41:8-15.

9. Feng J, Chen Q, Yu F, et al. Body mass index and risk of rheumatoid arthritis: a meta-analysis of observational studies. Medicine (Baltimore). 2016;95(8):e2859.

10. Mühlig Y, Antel J, Föcker M, Hebebrand J. Are bidirectional associations of obesity and depression already apparent in childhood and adolescence as based on high-quality studies? A systematic review. Obes Rev. 2016;17(3):235-249.

11. Binetti R, Costamagna FM, Marcello I. Exponential growth of new chemicals and evolution of information relevant to risk control. Ann Ist Super Sanita. 2008;44(1):12-15.

12. CAS [webpage on the Internet]. CAS Assigns the 100 Millionth CAS Registry Number to a Substance Designed to Treat Acute Myeloid Leukemia. Available from: cas.org; https:/www.cas.org/news/mediareleases/100-millionth-substance. Accessed October 25, 2016.

13. Lee H-R, Jeung E-B, Cho M-H, Kim T-H, Leung PCK, Choi K-C. Molecular mechanism(s) of endocrine-disrupting chemicals and their potent oestrogenicity in diverse cells and tissues that express oestrogen receptors. J Cell Mol Med. 2013;17(1):1-11.

14. Svechnikov K, Stukenborg J-B, Savchuck I, Söder O. Similar causes of various reproductive disorders in early life. Asian J Androl. 2014;16(1): 50-59.

15. Frye CA, Bo E, Calamandrei G, et al. Endocrine disrupters: a review of some sources, effects, and mechanisms of actions on behaviour and neuroendocrine systems. J Neuroendocrinol. 2012;24(1):144-159.

16. Knez J. Endocrine-disrupting chemicals and male reproductive health. Reprod Biomed Online. 2013;26(5):440-448.

17. Grün F, Blumberg B. Endocrine disrupters as obesogens. Mol Cell Endocrinol. 2009;304(1-2):19-29.

18. Tabb MM, Blumberg B. New modes of action for endocrine-disrupting chemicals. Mol Endocrinol. 2006;20(3):475-482. 
19. Norman RE, Carpenter DO, Scott J, Brune MN, Sly PD. Environmental exposures: an underrecognized contribution to noncommunicable diseases. Rev Environ Health. 2013;28(1):59-65.

20. Regnier SM, Sargis RM. Adipocytes under assault: environmental disruption of adipose physiology. Biochim Biophys Acta. 2014;1842(3): 520-533.

21. Carpenter DO. Environmental contaminants as risk factors for developing diabetes. Rev Environ Health. 2008;23(1):59-74.

22. Sargis RM, Johnson DN, Choudhury RA, Brady MJ. Environmental endocrine disruptors promote adipogenesis in the 3T3-L1 cell line through glucocorticoid receptor activation. Obesity (Silver Spring). 2010;18(7):1283-1288.

23. de Cock M, van de Bor M. Obesogenic effects of endocrine disruptors, what do we know from animal and human studies? Environ Int 2014;70:15-24

24. Panzica GC, Bo E, Martini MA, et al. Neuropeptides and enzymes are targets for the action of endocrine disrupting chemicals in the vertebrate brain. J Toxicol Environ Health B Crit Rev. 2011;14(5-7):449-472.

25. Legler J, Fletcher T, Govarts E, et al. Obesity, diabetes, and associated costs of exposure to endocrine-disrupting chemicals in the European Union. J Clin Endocrinol Metab. 2015;100(4):1278-1288.

26. Iszatt N, Stigum H, Verner MA, et al. Prenatal and postnatal exposure to persistent organic pollutants and infant growth: a pooled analysis of seven European birth cohorts. Environ Health Perspect. 2015;123(7):730-736.

27. de Cock M, De Boer MR, Lamoree M, Legler J, Van De Bor M. Prenatal exposure to endocrine disrupting chemicals and birth weight - a prospective cohort study. J Environ Sci Health A Tox Hazard Subst Environ Eng. 2016;51(2):178-185.

28. Stieb DM, Chen L, Hystad P, et al. A national study of the association between traffic-related air pollution and adverse pregnancy outcomes in Canada. Environ Res. 2016;148:513-526.

29. Hanson MA, Gluckman PD. Developmental origins of health and disease: new insights. Basic Clin Pharmacol Toxicol. 2008;102(2):90-93.

30. Dessì A, Ottonello G, Fanos V. Physiopathology of intrauterine growth retardation: from classic data to metabolomics. J Matern Fetal Neonatal Med. 2012;25(suppl 5):13-18.

31. Trasande L, Attina TM, Blustein J. Association between urinary bisphenol A concentration and obesity prevalence in children and adolescents. JAMA. 2012;308(11):1113-1121.

32. Whitehead R, Guan H, Arany E, Cernea M, Yang K. Prenatal exposure to bisphenol A alters mouse fetal pancreatic morphology and islet composition. Horm Mol Biol Clin Investig. 2016;25(3):171-179.

33. Veiga-Lopez A, Moeller J, Sreedharan R, et al. Developmental programming: interaction between prenatal BPA exposure and postnatal adiposity on metabolic variables in female sheep. Am J Physiol Endocrinol Metab. 2016;310(3):E238-E247.

34. Hatch EE, Nelson JW, Qureshi MM, et al. Association of urinary phthalate metabolite concentrations with body mass index and waist circumference: a cross-sectional study of NHANES data, 1999-2002. Environ Health. 2008;7:27.

35. Trasande L, Attina TM, Sathyanarayana S, Spanier AJ, Blustein J. Race/ethnicity-specific associations of urinary phthalates with childhood body mass in a nationally representative sample. Environ Health Perspect. 2013;121(4):501-506.

36. Buser MC, Murray HE, Scinicariello F. Age and sex differences in childhood and adulthood obesity association with phthalates: analyses of NHANES 2007-2010. Int J Hyg Environ Health. 2014;217(6):687-694.

37. Hu H, Kan H, Kearney GD, Xu X. Associations between exposure to polycyclic aromatic hydrocarbons and glucose homeostasis as well as metabolic syndrome in nondiabetic adults. Sci Total Environ. 2015;505:56-64.

38. Rancière F, Lyons JG, Loh V, et al. Bisphenol A and the risk of cardiometabolic disorders: a systematic review with meta-analysis of the epidemiological evidence. Environ Health. 2015;14:46.

39. James-Todd TM, Huang T, Seely EW, Saxena AR. The association between phthalates and metabolic syndrome: the National Health and Nutrition Examination Survey 2001-2010. Environ Health. 2016;15:52.
40. Nelson JW, Hatch EE, Webster TF. Exposure to polyfluoroalkyl chemicals and cholesterol, body weight, and insulin resistance in the general U.S. population. Environ Health Perspect. 2009;118(2):197-202.

41. Grün F, Blumberg B. Environmental obesogens: organotins and endocrine disruption via nuclear receptor signaling. Endocrinology. 2006;147(6 suppl):S50-S55.

42. Solomon KR, Williams WM, Mackay D, Purdy J, Giddings JM, Giesy JP. Properties and uses of chlorpyrifos in the United States. Rev Environ Contam Toxicol. 2014;231:13-34.

43. Brimble S, Bacchus P, Caux PY [webpage on the Internet]. Pesticide Utilization in Canada. Environment Canada; 2013. Available from: http://publications.gc.ca/site/eng/283211/publication.html. Accessed October 25, 2016.

44. Canada WSATDE. Presence and Levels of Priority Pesticides in Selected Canadian Aquatic Ecosystems. Canada WSATDE; 2011:1-111.

45. Riederer AM, Hunter RE, Hayden SW, Ryan PB. Pyrethroid and organophosphorus pesticides in composite diet samples from Atlanta, USA adults. Environ Sci Technol. 2010;44(1):483-490.

46. Bouvier G, Seta N, Vigouroux-Villard A, Blanchard O, Momas I. Insecticide urinary metabolites in nonoccupationally exposed populations. J Toxicol Environ Health B Crit Rev. 2005;8(6):485-512.

47. Curwin BD, Hein MJ, Sanderson WT, et al. Urinary pesticide concentrations among children, mothers and fathers living in farm and non-farm households in Iowa. Ann Occup Hyg. 2007;51(1):53-65.

48. Phung DT, Connell D, Miller G, et al. Biological monitoring of chlorpyrifos exposure to rice farmers in Vietnam. Chemosphere. 2012; 87(4):294-300.

49. Phung DT, Connell D, Yu Q, Chu C. Health risk characterization of chlorpyrifos using epidemiological dose-response data and probabilistic techniques: a case study with rice farmers in Vietnam. Risk Anal. 2013;33(9):1596-1607.

50. Slotkin TA, Brown KK, Seidler FJ. Developmental exposure of rats to chlorpyrifos elicits sex-selective hyperlipidemia and hyperinsulinemia in adulthood. Environ Health Perspect. 2005;113(10):1291-1294.

51. Meggs WJ, Brewer KL. Weight gain associated with chronic exposure to chlorpyrifos in rats. $J$ Med Toxicol. 2007;3(3):89-93.

52. Acker CI, Nogueira CW. Chlorpyrifos acute exposure induces hyperglycemia and hyperlipidemia in rats. Chemosphere. 2012;89(5):602-608.

53. Gordon CJ, Padnos BK. Prolonged elevation in blood pressure in the unrestrained rat exposed to chlorpyrifos. Toxicology. 2000;146(1): $1-13$.

54. Howell GE, Mulligan C, Young D, Kondakala S. Exposure to chlorpyrifos increases neutral lipid accumulation with accompanying increased de novo lipogenesis and decreased triglyceride secretion in McArdle-RH7777 hepatoma cells. Toxicol In Vitro. 2016;32:181-189.

55. Jeschke P, Nauen R, Schindler M, Elbert A. Overview of the status and global strategy for neonicotinoids. J Agric Food Chem. 2011;59(7): 2897-2908.

56. Anderson JC, Dubetz C, Palace VP. Neonicotinoids in the Canadian aquatic environment: a literature review on current use products with a focus on fate, exposure, and biological effects. Sci Total Environ. 2015;505:409-422.

57. Chen M, Tao L, McLean J, Lu C. Quantitative analysis of neonicotinoid insecticide residues in foods: implication for dietary exposures. J Agric Food Chem. 2014;62(26):6082-6090.

58. Brunet J-L, Maresca M, Fantini J, Belzunces LP. Human intestinal absorption of imidacloprid with Caco-2 cells as enterocyte model. Toxicol Appl Pharmacol. 2004;194(1):1-9.

59. Ueyama J, Nomura H, Kondo T, et al. Biological monitoring method for urinary neonicotinoid insecticides using LC-MS/MS and its application to Japanese adults. J Occup Health. 2014;56(6):461-468.

60. Kimura-Kuroda J, Komuta Y, Kuroda Y, Hayashi M, Kawano H. Nicotinelike effects of the neonicotinoid insecticides acetamiprid and imidacloprid on cerebellar neurons from neonatal rats. PLoS One. 2012;7(2):e32432.

61. Toor HK, Sangha GK, Khera KS. Imidacloprid induced histological and biochemical alterations in liver of female albino rats. Pestic Biochem Physiol. 2013;105(1):1-4. 
62. Vohra P, Khera KS. A Three Generation Study with effect of imidacloprid in rats: biochemical and histopathological investigation. Toxicol Int. 2015;22(1):119-124.

63. Gochberg-Sarver A, Kedmi M, Gana-Weisz M, Bar-Shira A, OrrUrtreger A. Tnf $\alpha$, Cox 2 and AdipoQ adipokine gene expression levels are modulated in murine adipose tissues by both nicotine and $\mathrm{nACh}$ receptors containing the $\beta 2$ subunit. Mol Genet Metab. 2012;107(3):561-570.

64. Park Y, Kim Y, Kim J, et al. Imidacloprid, a neonicotinoid insecticide, potentiates adipogenesis in 3T3-L1 adipocytes. J Agric Food Chem. 2013;61(1):255-259.

65. Kapoor U, Srivastava MK, Bhardwaj S, Srivastava LP. Effect of imidacloprid on antioxidant enzymes and lipid peroxidation in female rats to derive its No Observed Effect Level (NOEL). J Toxicol Sci. 2010;35(4):577-581.

66. Herrmann KM, Weaver LM. The shikimate pathway. Annu Rev Plant Physiol Plant Mol Biol. 1999;50(1):473-503.

67. Struger J, Van Stempvoort DR, Brown SJ. Sources of aminomethylphosphonic acid (AMPA) in urban and rural catchments in Ontario, Canada: glyphosate or phosphonates in wastewater? Environ Pollut. 2015;204:289-297.

68. Van Stempvoort DR, Roy JW, Brown SJ, Bickerton G. Residues of the herbicide glyphosate in riparian groundwater in urban catchments. Chemosphere. 2014;95:455-463.

69. Group WCA. Report of the Joint Meeting of the FAO Panel of Experts on Pesticide Residues in Food and the Environment and the WHO Core Assessment Group on Pesticide Residues Geneva, Switzerland, 15-24 September 2015.

70. Yoshioka N, Asano M, Kuse A, Mitsuhashi T, Nagasaki Y, Ueno Y. Rapid determination of glyphosate, glufosinate, bialaphos, and their major metabolites in serum by liquid chromatography-tandem mass spectrometry using hydrophilic interaction chromatography. J Chromatogr A. 2011;1218(23):3675-3680.

71. Motojyuku M, Saito T, Akieda K, Otsuka H, Yamamoto I, Inokuchi S. Determination of glyphosate, glyphosate metabolites, and glufosinate in human serum by gas chromatography-mass spectrometry. J Chromatogr B Analyt Technol Biomed Life Sci. 2008;875(2):509-514.

72. Aris A, Leblanc S. Maternal and fetal exposure to pesticides associated to genetically modified foods in Eastern Townships of Quebec, Canada. Reprod Toxicol. 2011;31(4):528-533.

73. de Araujo JSA, Delgado IF, Paumgartten FJR. Glyphosate and adverse pregnancy outcomes, a systematic review of observational studies. BMC Public Health. 2016;16:472.

74. Nation Pesticide Information Center. Glyphosate. Corvallis, OR: Nation Pesticide Information Center; 2015:1-3.

75. Mesnage R, Arno M, Costanzo M, Malatesta M, Séralini G-E, Antoniou MN. Transcriptome profile analysis reflects rat liver and kidney damage following chronic ultra-low dose Roundup exposure. Environ Health. 2015;14:70.

76. Martini CN, Gabrielli M, Vila MDC. A commercial formulation of glyphosate inhibits proliferation and differentiation to adipocytes and induces apoptosis in 3T3-L1 fibroblasts. Toxicol In Vitro. 2012;26(6):1007-1013.

77. Martini CN, Gabrielli M, Brandani JN, Vila MDC. Glyphosate inhibits PPAR gamma induction and differentiation of preadipocytes and is able to induce oxidative stress. J Biochem Mol Toxicol. 2016;30(8):404-413.

78. Gomes MP, Juneau P. Oxidative stress in duckweed (Lemna minor L.) induced by glyphosate: is the mitochondrial electron transport chain a target of this herbicide? Environ Pollut. 2016;218:402-409.

79. Rudich A, Tirosh A, Potashnik R, Hemi R, Kanety H, Bashan N. Prolonged oxidative stress impairs insulin-induced GLUT4 translocation in 3T3-L1 adipocytes. Diabetes. 1998;47(10):1562-1569.

80. Furukawa S, Fujita T, Shimabukuro M, et al. Increased oxidative stress in obesity and its impact on metabolic syndrome. J Clin Invest. 2004;114(12):1752-1761.

81. Annola K, Karttunen V, Keski-Rahkonen P, et al. Transplacental transfer of acrylamide and glycidamide are comparable to that of antipyrine in perfused human placenta. Toxicol Lett. 2008;182(1-3):50-56.
82. Takahashi M, Shibutani M, Nakahigashi J, et al. Limited lactational transfer of acrylamide to rat offspring on maternal oral administration during the gestation and lactation periods. Arch Toxicol. 2009;83(8):785-793.

83. El-Sayyad HI, Abou-Egla MH, El-Sayyad FI, et al. Effects of fried potato chip supplementation on mouse pregnancy and fetal development. Nutrition. 2011;27(3):343-350.

84. Allam AA, El-Ghareeb AW, Abdul-Hamid M, Bakery AE, Gad M, Sabri M. Effect of prenatal and perinatal acrylamide on the biochemical and morphological changes in liver of developing albino rat. Arch Toxicol. 2010;84(2):129-141.

85. SM R, Marie MA, Fahmy SR, El-Abied SA. Hazardous effects of acrylamide on immature male and female rats. Afr J Pharm Pharmacol. 2012;6(18):1367-1386.

86. Duarte-Salles T, Stedingk von H, Granum B, et al. Dietary acrylamide intake during pregnancy and fetal growth-results from the Norwegian mother and child cohort study (MoBa). Environ Health Perspect. 2013;121(3):374-379.

87. Pedersen M, Stedingk von H, Botsivali M, et al. Birth weight, head circumference, and prenatal exposure to acrylamide from maternal diet: the European prospective mother-child study (NewGeneris). Environ Health Perspect. 2012;120(12):1739-1745.

88. Kadawathagedara M, Tong ACH, Heude B, et al. Dietary acrylamide intake during pregnancy and anthropometry at birth in the French EDEN mother-child cohort study. Environ Res. 2016;149:189-196.

89. Mercier F, Glorennec P, Thomas O, Le Bot B. Organic contamination of settled house dust, a review for exposure assessment purposes. Environ Sci Technol. 2011;45(16):6716-6727.

90. Wu M-H, Xu B-T, Xu G, et al. Occurrence and profiles of polybrominated diphenyl ethers (PBDEs) in riverine sediments of Shanghai: a combinative study with human serum from the locals. Environ Geochem Health. Epub 2016 July 2.

91. Li B, Sun S-J, Huo C-Y, et al. Occurrence and fate of PBDEs and novel brominated flame retardants in a wastewater treatment plant in Harbin, China. Environ Sci Pollut Res Int. 2016;23(19):19246-19256.

92. Hoffman K, Garantziotis S, Birnbaum LS, Stapleton HM. Monitoring indoor exposure to organophosphate flame retardants: hand wipes and house dust. Environ Health Perspect. 2015;123(2):160-165.

93. Hoffman K, Webster TF, Sjödin A, Stapleton HM. Toddler's behavior and its impacts on exposure to polybrominated diphenyl ethers. $J$ Expo Sci Environ Epidemiol. Epub 2016 Mar 9.

94. Abbasi G, Saini A, Goosey E, Diamond ML. Product screening for sources of halogenated flame retardants in Canadian house and office dust. Sci Total Environ. 2016;54(5-546):299-307.

95. Dao T, Hong X, Wang X, Tang W-Y. Aberrant 5'-CpG methylation of cord blood TNF $\alpha$ associated with maternal exposure to polybrominated diphenyl ethers. PLoS One. 2015;10(9):e0138815.

96. Stasinska A, Heyworth J, Reid A, et al. Polybrominated diphenyl ether (PBDE) concentrations in plasma of pregnant women from Western Australia. Sci Total Environ. 2014;493:554-561.

97. Vorkamp K, Nielsen F, Kyhl HB, et al. Polybrominated diphenyl ethers and perfluoroalkyl substances in serum of pregnant women: levels, correlations, and potential health implications. Arch Environ Contam Toxicol. 2014;67(1):9-20.

98. Mathiesen L, Mørck TA, Zuri G, et al. Modelling of human transplacental transport as performed in Copenhagen, Denmark. Basic Clin Pharmacol Toxicol. 2014;115(1):93-100.

99. Rasinger JD, Carroll TS, Lundebye AK, Hogstrand C. Cross-omics gene and protein expression profiling in juvenile female mice highlights disruption of calcium and zinc signalling in the brain following dietary exposure to CB-153, BDE-47, HBCD or TCDD. Toxicology. 2014;321:1-12.

100. Chen A, Park J-S, Linderholm L, et al. Hydroxylated polybrominated diphenyl ethers in paired maternal and cord sera. Environ Sci Technol. 2013;47(8):3902-3908.

101. Rawn DFK, Gaertner DW, Weber D, Curran IHA, Cooke GM, Goodyer CG. Hexabromocyclododecane concentrations in Canadian human fetal liver and placental tissues. Sci Total Environ. 2014;46(8-469):622-629. 
102. Peltier MR, Koo H-C, Getahun D, Menon R. Does exposure to flame retardants increase the risk for preterm birth? J Reprod Immunol. 2015;107:20-25.

103. Müller MHB, Polder A, Brynildsrud OB, et al. Brominated flame retardants (BFRs) in breast milk and associated health risks to nursing infants in Northern Tanzania. Environ Int. 2016;8(9-90):38-47.

104. Lignell S, Aune M, Darnerud PO, Hanberg A, Larsson SC, Glynn A. Prenatal exposure to polychlorinated biphenyls (PCBs) and polybrominated diphenyl ethers (PBDEs) may influence birth weight among infants in a Swedish cohort with background exposure: a crosssectional study. Environ Health. 2013;12:44.

105. Lopez-Espinosa M-J, Costa O, Vizcaino E, et al. Prenatal exposure to polybrominated flame retardants and fetal growth in the INMA cohort (Spain). Environ Sci Technol. 2015;49(16):10108-10116.

106. Chen L, Wang C, Cui C, et al. Prenatal exposure to polybrominated diphenyl ethers and birth outcomes. Environ Pollut. 2015;206:32-37.

107. Harley KG, Chevrier J, Aguilar Schall R, Sjödin A, Bradman A, Eskenazi B. Association of prenatal exposure to polybrominated diphenyl ethers and infant birth weight. Am J Epidemiol. 2011;174(8):885-892.

108. Serme-Gbedo YK, Abdelouahab N, Pasquier J-C, Cohen AA, Takser L. Maternal levels of endocrine disruptors, polybrominated diphenyl ethers, in early pregnancy are not associated with lower birth weight in the Canadian birth cohort GESTE. Environ Health. 2016;15:49.

109. Guo W, Holden A, Smith SC, Gephart R, Petreas M, Park J-S. PBDE levels in breast milk are decreasing in California. Chemosphere. 2016; 150:505-513.

110. Nash JT, Szabo DT, Carey GB. Polybrominated diphenyl ethers alter hepatic phosphoenolpyruvate carboxykinase enzyme kinetics in male Wistar rats: implications for lipid and glucose metabolism. J Toxicol Environ Health Part A. 2013;76(2):142-156.

111. Hoppe AA, Carey GB. Polybrominated diphenyl ethers as endocrine disruptors of adipocyte metabolism. Obesity (Silver Spring). 2007; 15(12):2942-2950.

112. Lema SC, Dickey JT, Schultz IR, Swanson P. Dietary exposure to 2,2“,4,4-”tetrabromodiphenyl ether (PBDE-47) alters thyroid status and thyroid hormone-regulated gene transcription in the pituitary and brain. Environ Health Perspect. 2008;116(12):1694-1699.

113. Patisaul HB, Roberts SC, Mabrey N, et al. Accumulation and endocrine disrupting effects of the flame retardant mixture Firemaster ${ }^{\circledR}$ 550 in rats: an exploratory assessment. J Biochem Mol Toxicol. 2013; 27(2):124-136

114. Erkin-Cakmak A, Harley KG, Chevrier J, et al. In utero and childhood polybrominated diphenyl ether exposures and body mass at age 7 years: the CHAMACOS study. Environ Health Perspect. 2015;123(6):636-642.

115. Wang A, Padula A, Sirota M, Woodruff TJ. Environmental influences on reproductive health: the importance of chemical exposures. Fertil Steril. 2016;106(4):905-929.

116. Mussalo-Rauhamaa H, Leppänen A, Salmela SS, Pyysalo H. Cigarettes as a source of some trace and heavy metals and pesticides in man. Arch Environ Health. 1986;41(1):49-55.

117. Chang MJ, Walker K, McDaniel RL, Connell CT. Impaction collection and slurry sampling for the determination of arsenic, cadmium, and lead in sidestream cigarette smoke by inductively coupled plasma-mass spectrometry. J Environ Monit. 2005;7(12):1349-1354.
118. Tsoi M-F, Cheung C-L, Cheung TT, Cheung BMY. Continual decrease in blood lead level in Americans: United States National Health Nutrition and Examination Survey 1999-2014. Am J Med. 2016;129(11): 1213-1218.

119. Arbuckle TE, Liang CL, Morisset A-S, et al. Maternal and fetal exposure to cadmium, lead, manganese and mercury: the MIREC study. Chemosphere. 2016;163:270-282.

120. Rahman A, Kumarathasan P, Gomes J. Infant and mother related outcomes from exposure to metals with endocrine disrupting properties during pregnancy. Sci Total Environ. 2016;569-570:1022-1031.

121. Zheng T, Zhang J, Sommer K, et al. Effects of environmental exposures on fetal and childhood growth trajectories. Ann Glob Health. 2016;82(1):41-99.

122. Agay-Shay K, Martinez D, Valvi D, et al. Exposure to endocrine-disrupting chemicals during pregnancy and weight at 7 years of age: a multipollutant approach. Environ Health Perspect. 2015;123(10):1030-1037.

123. Afeiche M, Peterson KE, Sánchez BN, et al. Prenatal lead exposure and weight of 0- to 5-year-old children in Mexico city. Environ Health Perspect. 2011;119(10):1436-1441.

124. Padilla MA, Elobeid M, Ruden DM, Allison DB. An examination of the association of selected toxic metals with total and central obesity indices: NHANES 99-02. Int J Environ Res Public Health 2010;7(9):3332-3347.

125. Faulk C, Barks A, Sánchez BN, et al. Perinatal lead $(\mathrm{Pb})$ exposure results in sex-specific effects on food intake, fat, weight, and insulin response across the murine life-course. PLoS One. 2014;9(8):e104273.

126. Hawkesworth S, Wagatsuma Y, Kippler M, et al. Early exposure to toxic metals has a limited effect on blood pressure or kidney function in later childhood, rural Bangladesh. Int J Epidemiol. 2013;42(1):176-185.

127. Skröder H, Hawkesworth S, Kippler M, et al. Kidney function and blood pressure in preschool-aged children exposed to cadmium and arsenic - potential alleviation by selenium. Environ Res. 2015; 140:205-213.

128. Skröder H, Hawkesworth S, Moore SE, Wagatsuma Y, Kippler M, Vahter M. Prenatal lead exposure and childhood blood pressure and kidney function. Environ Res. 2016;151:628-634.

129. Sørensen N, Murata K, Budtz-Jørgensen E, Weihe P, Grandjean P. Prenatal methylmercury exposure as a cardiovascular risk factor at seven years of age. Epidemiology. 1999;10(4):370-375.

130. Kalish BT, Rifas-Shiman SL, Wright RO, et al. Associations of prenatal maternal blood mercury concentrations with early and mid-childhood blood pressure: a prospective study. Environ Res. 2014;133:327-333.

131. Pharmacopeial Convention US [webpage on the Internet]. USP to Implement Elemental Impurities Standards in January 2018. 2017. Available from: http://www.usp.org/news/usp-establishesjanuary-1-2018-implementation-date-elemental-impurities-standards. Accessed January 21, 2017.

132. China Water Risk [webpage on the Internet]. New 'Soil Ten Plan'To Safeguard China's Food Safety \& Healthy Living Environment. 2017. Available from: http://chinawaterrisk.org/notices/new-soil-ten-plan-tosafeguard-chinas-food-safety-healthy-living-environment/. Accessed January 21, 2017.

133. Heindel JJ, vom Saal FS, Blumberg G, et al. Parma consensus statement on metabolic disruptors. Environ Health. 2015;14:54.

Diabetes, Metabolic Syndrome and Obesity: Targets and Therapy

\section{Publish your work in this journal}

Diabetes, Metabolic Syndrome and Obesity: Targets and Therapy is an international, peer-reviewed open-access journal committed to the rapid publication of the latest laboratory and clinical findings in the fields of diabetes, metabolic syndrome and obesity research Original research, review, case reports, hypothesis formation, expert opinion and commentaries are all considered for publication. The manuscript management system is completely online and includes a very quick and fair peer-review system, which is all easy to use. Visit http://www.dovepress.com/testimonials.php to read real quotes from published authors. 